\title{
Who Has an Unsuccessful Observation Care Stay?
}

\author{
Gelareh Z. Gabayan ${ }^{1, *}$, Brian Doyle ${ }^{2}$, Li-Jung Liang ${ }^{3}$, Kwame Donkor ${ }^{1,4}$, \\ David Yu-Chuang Huang ${ }^{3}$ and Catherine A. Sarkisian ${ }^{4,5}$ \\ 1 Department of Emergency Medicine, University of California, Los Angeles, CA 90024, USA; \\ kapdonkor@gmail.com \\ 2 Department of Internal Medicine, Ohio State University, Columbus, OH 43210, USA; doylebr@gmail.com \\ 3 Divisions of General Internal Medicine and Health Services Research, David Geffen School of Medicine at \\ UCLA, Los Angeles, CA 90095, USA; liangl@ucla.edu (L.-J.L.); YCHuang@mednet.ucla.edu (D.Y.-C.H.) \\ 4 Department of Medicine, Greater Los Angeles Veterans Affairs Healthcare System, Geriatric Research \\ Education and Clinical Center (GRECC), Los Angeles, CA 90073, USA; CSarkisian@mednet.ucla.edu \\ 5 Department of Medicine, University of California, Los Angeles, CA 90024, USA \\ * Correspondence: Gelareh@gabayan.com; Tel.: +1-310-490-2140; Fax: +1-310-740-7600
}

Received: 23 August 2018; Accepted: 19 November 2018; Published: 27 November 2018

\begin{abstract}
Background: With the recent increase use of observation care, it is important to understand the characteristics of patients that utilize this care and either have a prolonged observation care stay or require admission. Methods: We a conducted a retrospective cohort study utilizing $5 \%$ sample data from Medicare patients age $\geq 65$ years that was nationally representative in the year 2013. We performed a generalized estimating equation (GEE) logistic regression analysis to evaluate the relationship between an unsuccessful observation stay (defined as either requiring an inpatient admission from observation or having a prolonged observation stay) compared to having successful observation care. Observation cut offs of "successful" vs. "unsuccessful" were based on the CMS 2 midnight rule. Results: Of 154,756 observation stays in 2013, 19 percent $(n=29,604)$ were admitted to the inpatient service and $34,275(22.2 \%)$ had a prolonged observation stay. The two diagnoses most likely to have an unsuccessful observation stay were intestinal infections (OR 1.56, 95\% CI 1.32-1.83) and pneumonia (OR 1.26, 95\% CI 1.13-1.41). Conclusion: We found patients placed in observation care with intestinal infections and pneumonia to have the highest odds of either being admitted from observation or having a prolonged observation stay.
\end{abstract}

Keywords: observation care; outcomes; unsuccessful observation care; observation failure

\section{Introduction}

In recent years, there has been greater use of observation services for patients by all types of providers [1-3] This care provides a short-term (24-72 h) treatment and assessment, is billed as an outpatient visit, and can take place in the emergency department, inpatient units, special observation units, or any other monitored settings [4] It is utilized by providers to "observe" patients in a monitored setting, usually a hospital. Patients placed in observation care are not well enough to be discharged home and not sick enough to require a prolonged admission. Due to the nature of observation care, patients placed in this care are not expected to require prolonged monitored care.

While the idea of observing a patient dates back to Hippocrates, the increased use of observation care in the US is relatively new [5]. As providers better understand the roles and uses of observation care stays, they require an improved understanding of the outcomes of patients placed in observation care. For inpatient providers and hospital administrators, patients who have unsuccessful observation stays either require an inpatient admission or to have a prolonged observation stay. It is important for both providers and administrators to understand the characteristics of these patients as unsuccessful 
observation stays are costly to the system, not clinically expected, and may result in unnecessary care. Currently, there are no known studies that assess the characteristics of patients who have an unsuccessful observation stay.

We evaluated 154,756 patients with Medicare Insurance age $\geq 65$ years placed in any US hospital observation care in 2013. The objective of the study was to evaluate the characteristics of patients who utilize observation care and subsequently have an unsuccessful stay, either by being admitted to the inpatient service or by having a prolonged observation stay, defined as $\geq 2$ midnights.

\section{Methods}

\subsection{Study Design}

We performed a retrospective cohort study of a 5\% sample of Medicare patients that was nationally representative. All patients were placed in observation care in 2013. The IRB at the University of California, Los Angeles approved the study.

\subsection{Setting and Selection of Participants}

Participants in the study were age $\geq 65$ years at the time of their first day of observation care use. If participants had multiple observation care stays, then only the first stay of the year was included in the analytic sample. Patients who had an observation stay more than 30 days or who were deceased during the observation stay were excluded.

\subsection{Data Sources}

Visit records used for the study analysis were obtained from the Center for Medicare and Medicaid (CMS) Outpatient File, the CMS Inpatient MEDPAR (Medicare Provider Analysis and Review) file, the Master Beneficiary File, and the Chronic Conditions file for 2013.

\subsection{Measures}

Patient comorbidities were derived through the CMS Chronic Conditions file which was linked to the visit records using Claim ID. The CMS Chronic Conditions file contains information regarding the sum total of chronic conditions prior to the observation stay (0-27). Medical diagnoses were obtained based on an algorithm developed by the PI of the study [6-8]. In brief, a cross-walk mapping process was linked to the primary ICD-9 code for each observation stay through use of the Multi-level Clinical Classification system (CCS) codes provided by the Healthcare Cost and Utilization Project (HCUP) [9]. The PI developed a total of 39 categories, which have been outlined in the Appendix A. Having used the emergency department (ED) immediately prior to the observation stay, inpatient admission, and use of a skilled nursing facility (SNF) were determined based on Revenue Center Codes as well as charges made to Medicare.

Observation care cut-offs (successful vs. unsuccessful) were based on the CMS 2 midnight rule billing criteria [10] as well as discussion with a set of hospital administrators and inpatient physicians at UCLA and other hospitals. The terms "successful" vs. "unsuccessful" were also obtained through discussion with the administrators and providers. "Unsuccessful" was defined as having at least 2 midnight observation stays or being transferred to the inpatient service. Observation stays of 0 days required at least an $8 \mathrm{~h}$ placement in observation care to be billed as "observation". Each day of observation care usage (i.e., 1 or 30 ) required the same number of midnights as days.

\subsection{Data Analysis}

Patient characteristics (demographic and clinical) as well as the diagnoses were summarized for the two clinical outcomes following an observation stay (successful observation care stay and unsuccessful observation care stay). In addition, both descriptive statistics and frequency distributions for continuous and categorical variables were generated. 
Candidate factors included demographic characteristics, patient comorbidities proxied by the number of CMS chronic conditions, and observation care diagnoses. Clinical Outcomes were modeled using a Generalized Estimating Equation (GEE) logistic regression [11]. The model included all candidate factors as fixed effects and provider-level random effects that accounted for multiple observations within providers.

The model evaluated the factors associated with unsuccessful observation care (inpatient admission from observation care or observation care 2-30 days) vs. successful observation care ( 0 or 1 days/midnights of observation care which equates to a maximum of $47 \mathrm{~h}$ and $59 \mathrm{~min}$ ). Adjusted odds ratios (AOR) and 95\% confidence interval estimates were generated from this analysis. The reference groups for all analyses were the following: Age 65-69, female gender, weekday initial observation placement, observation placement from a non-ED, never used a SNF, no chronic conditions, and observation care diagnosis of "Urinary Tract Infection". In addition, the study group conducted additional sensitivity analyses regarding patients who attended the ED and weekend vs. weekday visits.

\section{Results}

\subsection{Sample Characteristics}

Table 1 describes the characteristics of the sample. There were close to twice the number of female patients as compared to male $(96,742$ vs. 57,994). Fifteen percent of the cohort were placed in observation on the weekend and over half of the number of patients placed in observation came from the emergency department. Of all patients placed in observation care, a total of 64,215 (41.5\%) came from the ED on a weekday and 21,500 (13.9\%) came from the ED on a weekend day. Table 2 describes the diagnoses of the patients with observation stays and their outcomes. Of all diagnoses, diseases of the musculoskeletal system resulted in the highest number of patients placed in observation care $(\mathrm{N}=17,401)$. This diagnosis also had the highest percent of placement $(76.3 \%)$ in successful observation care. The diagnosis with the greatest number of admissions from observation was pneumonia $(1077 / 1857,58 \%)$. The diagnosis with the greatest percent of prolonged observation was abdominal pain $(36.1 \%)$.

Table 1. Observation sample characteristics.

\begin{tabular}{|c|c|c|c|c|}
\hline Characteristic & $\begin{array}{l}\text { Total } \\
(\mathrm{N})\end{array}$ & $\underset{(\%)}{\text { Admitted N }}$ & $\begin{array}{c}\text { OBS 2-30 Days } \\
\text { N (\%) }\end{array}$ & $\begin{array}{c}\text { OBS } 0 \text { or } 1 \text { Day } \\
N(\%)\end{array}$ \\
\hline \multicolumn{5}{|l|}{ Age $^{1}$} \\
\hline $65-69$ & 31,219 & $4636(14.9)$ & $5983(19.2)$ & $20,600(65.9)$ \\
\hline $70-74$ & 30,182 & $4954(16.4)$ & $5986(19.8)$ & $19,242(63.8)$ \\
\hline $75-79$ & 29,487 & $5583(18.9)$ & $6368(21.6)$ & $17,536(59.5)$ \\
\hline $80+$ & 63,866 & $14,431(22.6)$ & $15,938(25.0)$ & $33,499(52.4)$ \\
\hline \multicolumn{5}{|l|}{ Gender } \\
\hline Female & 96,762 & $18,567(19.2)$ & $22,577(23.3)$ & $55,618(57.5)$ \\
\hline Male & 57,994 & $11,037(19.0)$ & $11,698(20.2)$ & $35,259(60.8)$ \\
\hline \multicolumn{5}{|l|}{ Race/Ethnicity ${ }^{4}$} \\
\hline White & 134,753 & $25,158(18.7)$ & $29,317(21.8)$ & $80,278(59.6)$ \\
\hline lack & 13,215 & $3045(23.0)$ & $3421(25.9)$ & $6749(51.1)$ \\
\hline Asian & 1885 & $414(22.0)$ & $420(22.3)$ & $1051(55.8)$ \\
\hline Hispanic & 2156 & $538(25.0)$ & $547(25.4)$ & $1071(49.7)$ \\
\hline North American N & 645 & $92(14.3)$ & $168(26.0)$ & $385(59.7)$ \\
\hline \multicolumn{5}{|l|}{ Day of week of service } \\
\hline Weekday & 131,486 & $22,631(17.2)$ & $27,549(21.0)$ & $81,306(61.8)$ \\
\hline Weekend & 23,270 & $6973(30.0)$ & $6726(28.9)$ & $9571(41.1)$ \\
\hline
\end{tabular}


Table 1. Cont.

\begin{tabular}{|c|c|c|c|c|}
\hline Characteristic & $\begin{array}{l}\text { Total } \\
\text { (N) }\end{array}$ & $\underset{(\%)}{\text { Admitted N }}$ & $\begin{array}{c}\text { OBS 2-30 Days } \\
\text { N (\%) }\end{array}$ & $\begin{array}{c}\text { OBS } 0 \text { or } 1 \text { Day } \\
\text { N (\%) }\end{array}$ \\
\hline \multicolumn{5}{|l|}{ Observation care from an ED } \\
\hline NO & 69,041 & $4001(5.8)$ & $11,286(16.3)$ & $53,754(77.9)$ \\
\hline YES & 85,715 & $25,603(29.9)$ & $22,989(26.8)$ & $37,123(43.3)$ \\
\hline \multicolumn{5}{|l|}{ SNF $^{2}$ utilization } \\
\hline NO & 74,420 & $1(0)$ & 17,045 (22.9) & $57,374(77.1)$ \\
\hline YES & 80,336 & $29,603(36.8)$ & $17,230(21.5)$ & $33,503(41.7)$ \\
\hline \multicolumn{5}{|l|}{ Comorbidity $^{3}$} \\
\hline Acute Myocardial Infarction & 12,860 & $2932(22.8)$ & $3108(24.2)$ & $6820(53.0)$ \\
\hline Alzheimer's Disease & 12,844 & $3113(24.2)$ & $3721(29.0)$ & $6010(46.8)$ \\
\hline Alzheimer's Disease and Related Disorders & 32,060 & $7578(23.6)$ & $9106(28.4)$ & $15,376(48.0)$ \\
\hline Atrial Fibrillation & 36,946 & $7815(21.2)$ & $9088(24.6)$ & $20,043(54.2)$ \\
\hline Cataract & 109,907 & $19,547(17.8)$ & $25,474(23.2)$ & $64,886(59.0)$ \\
\hline Chronic Kidney Disease & 55,218 & $11,993(21.7)$ & $13,873(25.1)$ & $29,352(53.2)$ \\
\hline Chronic Obstructive Pulmonary Disease & 56,578 & $12,029(21.3)$ & $14,175(25.1)$ & $30,374(53.7)$ \\
\hline Heart Failure & 62,989 & $14,094(22.4)$ & $16,040(25.5)$ & $32,855(52.2)$ \\
\hline Diabetes & 66,402 & $13,334(20.1)$ & $16,143(24.3)$ & $36,925(55.6)$ \\
\hline Glaucoma & 37,932 & $6681(17.6)$ & $8980(23.7)$ & $22,271(58.7)$ \\
\hline Hip/Pelvic Fracture & 9112 & $2119(23.3)$ & $2456(27.0)$ & $4537(49.8)$ \\
\hline Ischemic Heart Disease & 97,143 & $19,525(20.1)$ & $23,272(24.0)$ & $54,346(55.9)$ \\
\hline Depression & 59,719 & $11,590(19.4)$ & $14,993(25.1)$ & $33,136(55.5)$ \\
\hline Osteoporosis & 43,268 & $8067(18.6)$ & $10,805(25.0)$ & $24,396(56.4)$ \\
\hline Rheumatoid Arthritis/Osteoarthritis & 101,301 & $18,242(18.0)$ & $24,036(23.7)$ & $59,023(58.3)$ \\
\hline Stroke/Transient Ischemic Attack & 35,114 & $7997(22.8)$ & $9170(26.1)$ & $17,947(51.1)$ \\
\hline Breast Cancer & 12,449 & $1843(14.8)$ & $2939(23.6)$ & $7667(61.6)$ \\
\hline Colorectal Cancer & 6647 & $1212(18.2)$ & $1620(24.4)$ & $3815(57.4)$ \\
\hline Prostate Cancer & 10,135 & $1663(16.4)$ & $2074(20.5)$ & $6398(63.1)$ \\
\hline Lung Cancer & 4644 & $789(17.0)$ & $1119(24.1)$ & $2736(58.9)$ \\
\hline Endometrial Cancer & 2167 & $345(15.9)$ & $539(24.9)$ & $1283(59.2)$ \\
\hline Anemia & 100,552 & $19,592(19.5)$ & $24,596(24.5)$ & $56,364(56.1)$ \\
\hline Asthma & 27,545 & $5612(20.4)$ & $6807(24.7)$ & $15,126(54.9)$ \\
\hline Hyperlipidemia & 125,221 & $22,660(18.1)$ & $28,804(23.0)$ & $73,757(58.9)$ \\
\hline Benign Prostatic Hyperplasia & 30,077 & $5293(17.6)$ & $6521(21.7)$ & $18,263(60.7)$ \\
\hline Hypertension & 134,494 & $25,096(18.7)$ & $31,324(23.3)$ & $78,074(58.1)$ \\
\hline Acquired Hypothyroidism & 47,856 & $9040(18.9)$ & $11,673(24.4)$ & $27,143(56.7)$ \\
\hline
\end{tabular}

${ }^{1}$ Age at observation admission. ${ }^{2}$ Skilled Nursing Facility utilization in 2013. ${ }^{3}$ Comorbidity based on the CMS Chronic Conditions. ${ }^{4}$ Of race/ethnicity was, $1 \%$ was reported as "Other" and $0.4 \%$ was unknown.

Table 2. Observation sample diagnoses $(\mathrm{N}=154,756)$.

\begin{tabular}{|c|c|c|c|c|}
\hline \multirow[t]{2}{*}{ Characteristic } & $\begin{array}{c}\text { Total } \\
(\mathrm{N}=154,756)\end{array}$ & $\begin{array}{l}\text { Obs 0-1 Day } \\
(N=90,877)\end{array}$ & $\begin{array}{c}\text { Admitted } \\
(\mathrm{N}=29,604)\end{array}$ & $\begin{array}{c}\text { Obs 2-30 Days } \\
(\mathrm{N}=34,275)\end{array}$ \\
\hline & $\mathbf{N}(\%)$ & N (\%) & $\mathbf{N}(\%)$ & $\mathbf{N}(\%)$ \\
\hline Chest pain & $15,202(9.8)$ & $11,283(74.2)$ & $707(4.7)$ & $3212(21.1)$ \\
\hline Neoplasms & $12,298(7.9)$ & $9142(74.3)$ & $840(6.8)$ & $2316(18.8)$ \\
\hline GI System Diseases & $9932(6.4)$ & $4295(43.2)$ & $3120(31.4)$ & $2517(25.3)$ \\
\hline Dysrhythmias and condition disorders & $6169(4)$ & $3430(55.6)$ & $1639(26.6)$ & $1100(17.8)$ \\
\hline Nervous System Disorders & $5725(3.7)$ & $3935(68.7)$ & $728(12.7)$ & $1062(18.6)$ \\
\hline Ischemic Heart Disease & $5346(3.5)$ & $2421(45.3)$ & $2055(38.4)$ & $870(16.3)$ \\
\hline Endocrine nutritional immunity and metabolic disorders & $5066(3.3)$ & $2782(54.9)$ & $984(19.4)$ & $1300(25.7)$ \\
\hline Other Renal and GU Diseases & $4941(3.2)$ & $3572(72.3)$ & $436(8.8)$ & $933(18.9)$ \\
\hline Other Respiratory Disease & $3240(2.1)$ & $2182(67.3)$ & $439(13.5)$ & $619(19.1)$ \\
\hline Urinary Tract Infection & $3218(2.1)$ & $1014(31.5)$ & $1320(41)$ & $884(27.5)$ \\
\hline Diseases of the blood & $3122(2)$ & $2007(64.3)$ & $462(14.8)$ & $653(20.9)$ \\
\hline
\end{tabular}


Table 2. Cont

\begin{tabular}{|c|c|c|c|c|}
\hline \multirow[t]{2}{*}{ Characteristic } & $\begin{array}{c}\text { Total } \\
(\mathrm{N}=154,756)\end{array}$ & $\begin{array}{l}\text { Obs 0-1 Day } \\
(N=90,877)\end{array}$ & $\begin{array}{c}\text { Admitted } \\
(N=29,604)\end{array}$ & $\begin{array}{c}\text { Obs 2-30 Days } \\
(\mathrm{N}=34,275)\end{array}$ \\
\hline & $\mathbf{N}(\%)$ & $\mathbf{N}(\%)$ & $\mathbf{N}(\%)$ & $\mathbf{N}(\%)$ \\
\hline Congestive Heart Failure & $2994(1.9)$ & $871(29.1)$ & $1476(49.3)$ & $647(21.6)$ \\
\hline Complications and Adverse events & $2958(1.9)$ & $1363(46.1)$ & $922(31.2)$ & $673(22.8)$ \\
\hline Other Symptoms & $2699(1.7)$ & $1512(56)$ & $252(9.3)$ & $935(34.6)$ \\
\hline Other Infectious and Parasitic Diseases & $2343(1.5)$ & $954(40.7)$ & $1166(49.8)$ & $223(9.5)$ \\
\hline Pneumonia & $1857(1.2)$ & $444(23.9)$ & $1077(58)$ & $336(18.1)$ \\
\hline Abdominal pain & $1644(1.1)$ & $914(55.6)$ & $137(8.3)$ & $593(36.1)$ \\
\hline Renal Disease & $1642(1.1)$ & $471(28.7)$ & $899(54.8)$ & $272(16.6)$ \\
\hline Mental Illness & $1592(1)$ & $730(45.9)$ & $384(24.1)$ & $478(30)$ \\
\hline
\end{tabular}

Total sample included all patients in the study cohort: Row percents are presented. Patients with a $<1 \%$ diagnosis not included.

\subsection{Main Results}

Figure A1 (Appendix A) describes the creation of the study cohort. There were 154,756 with an initial observation stay in 2013. Of the cohort placed in observation, 29,604 (19.1\%) were admitted to the inpatient service and 34,275 (22.2\%) had a prolonged observation stay. Table 3 describes the GEE results of the model assessing the factors associated with an unsuccessful observation stay (admission or $>2$ days) vs. successful observation care (0-1 days). The top two diagnoses most likely to have an unsuccessful observation stay were intestinal infections (AOR 1.56, 95\% CI 1.32-1.83) and pneumonia (AOR 1.26, 95\% CI 1.13-1.41). Patients placed in observation care on a weekend (AOR 1.28, 95\% CI 1.24-1.32), came from the emergency department (AOR 2.84, 95\% CI 2.74-2.95) or utilized a skilled nursing facility (AOR 2.85, 95\% CI 2.68-3.02) also had high odds of an unsuccessful observation stay.

Table 3. GEE logistic regression for unsuccessful observation care stay.

\begin{tabular}{lcc}
\hline \multicolumn{1}{c}{ Patient Characteristics } & Odds Ratio (95\% CI) & $p$ \\
\hline Age (REF = 65-69) & & \\
$\quad 70-74$ & $1.05(1.01-1.09)$ & 0.0066 \\
$75-79$ & $1.14(1.1-1.18)$ & $<0.0001$ \\
$80+$ & $1.23(1.19-1.27)$ & $<0.0001$ \\
\hline Gender & & \\
$\quad$ Male vs. Female & $0.92(0.9-0.94)$ & $<0.0001$ \\
\hline Race/Ethnicity (REF = White) & & \\
$\quad$ Black & $1.22(1.17-1.27)$ & $<0.0001$ \\
$\quad$ Others & $1.06(0.97-1.15)$ & 0.2049 \\
$\quad$ Asian/PI & $1.17(1.05-1.31)$ & 0.0051 \\
$\quad$ Hispanic & $1.11(1.01-1.22)$ & 0.036 \\
\hline $\begin{array}{l}\text { Day of week of service } \\
\quad \text { Weekend vs. Weekday }\end{array}$ & $1.28(1.24-1.32)$ & $<0.0001$ \\
\hline $\begin{array}{l}\text { Observation care from an ED visit } \\
\quad \text { Yes vs. No }\end{array}$ & $2.84(2.74-2.95)$ & $<0.0001$ \\
\hline Ever used SNF services in 2013 & & \\
$\quad$ Yes vs. No & & $<0.0001$ \\
$\quad$ Number of chronic conditions ${ }^{1}$ & $2.85(2.68-3.02)$ & $<0.0001$ \\
\hline
\end{tabular}


Table 3. Cont.

\begin{tabular}{|c|c|c|}
\hline Patient Characteristics & Odds Ratio (95\% CI) & $p$ \\
\hline \multicolumn{3}{|l|}{ Observation diagnosis $(\mathrm{REF}=$ Urinary Tract Infection) } \\
\hline Intestinal Infection & $1.56(1.32-1.83)$ & $<0.0001$ \\
\hline Pneumonia & $1.26(1.13-1.41)$ & $<0.0001$ \\
\hline Other Infectious and Parasitic Diseases ${ }^{2}$ & $1.13(1.01-1.27)$ & 0.0278 \\
\hline Renal Disease & $1.08(0.96-1.23)$ & 0.2008 \\
\hline Skin and Subcutaneous Infections & $1.04(0.93-1.18)$ & 0.4759 \\
\hline $\mathrm{CHF}$ & $0.97(0.88-1.07)$ & 0.5597 \\
\hline Asthma & $0.96(0.82-1.13)$ & 0.6567 \\
\hline Minor Injuries & $0.86(0.79-0.94)$ & 0.0009 \\
\hline GI system Diseases & $0.83(0.76-0.89)$ & $<0.0001$ \\
\hline COPD & $0.82(0.75-0.91)$ & $<0.0001$ \\
\hline Non-atherosclerotic Heart Disease & $0.79(0.68-0.91)$ & 0.0012 \\
\hline Non-infectious Lung Disease & $0.76(0.65-0.88)$ & 0.0004 \\
\hline Complications and Adverse events & $0.75(0.68-0.83)$ & $<0.0001$ \\
\hline Ischemic Heart Disease & $0.73(0.67-0.81)$ & $<0.0001$ \\
\hline Circulatory Disorders & $0.73(0.66-0.81)$ & $<0.0001$ \\
\hline Cerebrovascular Diseases & $0.72(0.66-0.79)$ & $<0.0001$ \\
\hline Mental Illness & $0.65(0.57-0.74)$ & $<0.0001$ \\
\hline Upper Respiratory Infection & $0.64(0.56-0.72)$ & $<0.0001$ \\
\hline Diabetes Mellitus & $0.62(0.55-0.7)$ & $<0.0001$ \\
\hline Endocrine, nutritional, immunity and metabolic disorders & $0.6(0.55-0.65)$ & $<0.0001$ \\
\hline Neoplasms & $0.59(0.54-0.66)$ & $<0.0001$ \\
\hline Other Renal and GI Diseases & $0.58(0.52-0.64)$ & $<0.0001$ \\
\hline Dysrhythmias & $0.53(0.49-0.59)$ & $<0.0001$ \\
\hline Congenital Diseases & $0.53(0.34-0.83)$ & 0.0058 \\
\hline Major Injuries & $0.52(0.43-0.63)$ & $<0.0001$ \\
\hline Nervous system Disorders & $0.51(0.46-0.56)$ & $<0.0001$ \\
\hline Other Injuries & $0.49(0.44-0.55)$ & $<0.0001$ \\
\hline Diseases of the musculoskeletal system, skin and connective tissue & $0.49(0.45-0.53)$ & $<0.0001$ \\
\hline Hypertension & $0.48(0.43-0.54)$ & $<0.0001$ \\
\hline Symptoms: Abdominal Pain & $0.47(0.42-0.54)$ & $<0.0001$ \\
\hline Symptoms: Others & $0.47(0.42-0.51)$ & $<0.0001$ \\
\hline Diseases of the blood & $0.45(0.4-0.51)$ & $<0.0001$ \\
\hline Other Residual Codes & $0.42(0.38-0.47)$ & $<0.0001$ \\
\hline Symptoms: Dizziness, Vertigo and Syncope & $0.38(0.35-0.42)$ & $<0.0001$ \\
\hline Other Respiratory Diseases & $0.38(0.34-0.42)$ & $<0.0001$ \\
\hline Symptoms: Headache & $0.32(0.26-0.41)$ & $<0.0001$ \\
\hline Symptoms: Chest Pain & $0.17(0.16-0.19)$ & $<0.0001$ \\
\hline
\end{tabular}

Unsuccessful Observation Care Stay defined as an observation stay that resulted in Admission or a prolonged Observation stay defined as a stay 2-30 days. ${ }^{1}$ Number of CMS Chronic Conditions based on 0-27 conditions.

${ }^{2}$ Including Meningitis, Infective Arthritis, Bacterial, Mycoses, Viral.

\section{Discussion}

In recent years, there has been a greater use of observation care $[1,2,12,13]$ This type of "temporary" care allows providers to place patients in a monitored setting, usually a hospital, where they can be watched for 0-48 h while being considered an outpatient encounter [5] For providers, administrators, and health policy experts, it is important to understand the type of patients that have an unsuccessful observation stay, defined as either having a prolonged observation stay or getting admitted from observation care, as having an unsuccessful observation care stay is not only unexpected to the health care system but it may result in greater cost and unnecessary care for the system. We found that patients with intestinal infections and pneumonia have the highest likelihood of having an unsuccessful observation care stay. In addition, we also found that patients coming from the ED, seen on a weekend as compared to weekday, and having been placed in a skilled nursing facility to have a higher rate of an unsuccessful observation stay.

The diagnosis with the highest odds of having an unsuccessful observation care stay was an intestinal infection, ranging from a rare diagnosis such as Cholera or Shigella to an ill-defined diagnosis. An intestinal infection is commonly a condition that is transitory in nature and while physically 
uncomfortable, less likely to require aggressive treatment. The findings of this study suggest that if a patient requires placement in the hospital, there may be additional factors not identifiable in administrative data that could lead to prolonged care such as dehydration and/or requirement of an extended course of treatment.

Pneumonia had the second highest odds of an unsuccessful observation care stay. Over 50\% of pneumonias are classified as community acquired pneumonia [14]. While the epidemiology and bacteriology of all the types of pneumonia are different, on initial presentation a provider is unable to distinguish between the different kinds of pneumonia until further testing is done [15]. As pneumonia is an infection that can have an unpredictable course, it is understandable that patients with pneumonia had a high rate of an unsuccessful observation care stay. It is also possible that patients with pneumonia were misdiagnosed.

We found that originating from the emergency department had a high odds of an unsuccessful observation care stay. Patients placed in observation care can range between having come from an acute encounter or a scheduled procedure and providers in the ED often lack historical information on patients [5]. The unpredictability of the type of patents presenting to the ED as well as the lack of history may lead to ED providers not understanding the complexity of care patients may need. It is important for health care administrators to be aware of these finding so that if patients do originate from the ED, they receive a more defined method of management.

Patients placed in observation care on a weekend had a higher likelihood of an unsuccessful observation care stay. This could be a result of multiple factors. Care delivered to patients on weekends does not often include the complete staff and services needed. In addition, patients may have prolonged seeing a provider until the weekend and the condition could have worsened. Although the study controlled for number of comorbidities and conditions, it was unable to account for severity of illness.

Patients in a skilled nursing facility (SNF) usually have a greater number of medical problems and require more ancillary care [16] As these patients are more "complex" it would be expected that they would have a greater likelihood of having a prolonged observation stay or requiring admission following their observation care. In the same light, it would lead to an excess in resource utilization if all patients from a SNF were admitted. Providers seeing these patients should continue to evaluate and develop a disposition plan based on need but should keep in mind that these patients have a higher likelihood of not being successful in their observation care stay.

\section{Limitations}

The study has some limitations. First, the analysis is based on data derived from claim ID, billing data, and ICD-9 codes, which are limited in that they are retrospective and can reflect incomplete coding. Second, a majority of patients who use Medicare insurance do not visit Federal hospitals, so these findings are not generalizable to Federal facilities [3]. Third, the analysis did not include information from prior year observation stays as that would require use of data from a prior year that the team did not have. Also, the files lack clinical variables such as vital signs and physical exam. The files also lack information regarding hospital characteristics such as teaching vs. non, rural vs. non, average income of hospitals, etc. Finally, the data is several years old as a result of the time it took to acquire ( 2 years), link and clean the files ( 2 years). Despite these limitations, this study provides important information regarding older Medicare beneficiaries that experience observation stay.

\section{Conclusions}

With the rise of observation care utilization, we assessed the factors associated with having an unsuccessful observation care stay. Patients with either an intestinal infection or pneumonia had the highest odds of an unsuccessful observation care stay. In addition, patients coming from the emergency department, placed in observation care on a weekend, or requiring a skilled nursing facility had the highest likelihood of lack of observation success. This study provides relevant and essential information for both providers and hospital administrators. 
Author Contributions: G.Z.G. conceived of the study and obtained funding. C.A.S., L.-J.L., K.D. and B.D. aided in the design of the study and C.A.S. supervised the conduct of the study. L.-J.L. and D.Y.-C.H. managed the data, provided statistical advice, and conducted analyses. G.Z.G. drafted the report and all authors contributed substantially to its revision. G.Z.G. takes responsibility for the report as a whole.

Funding: This research and Gabayan were supported by the NIH/NIA Grant for Early Medical/Surgical Specialists Transition to Aging Research Grant (GEMSSTAR R03AG047862-01) and the American Geriatric Society Jahnigen Award. Sarkisian is currently supported by the NIH/NIA UCLA Resource Center for Minority Aging Research/Center for Health Improvement of Minority Elders (RCMAR/CHIME) (2P30AG081684); NIH/NIA Mid-career Award in Patient-Oriented Research (1K24AGO47899); and the NIH National Center for Advancing Translational Science (NCATS) UCLA CTSI Grant Number (UL1TR001881). The content is solely the responsibility of the authors and does not represent the official views of the NIH. None of the authors have any financial, consultant, institutional, or other conflicts of interest or relationships.

Conflicts of Interest: The authors declare no conflict of interest.

\section{Appendix A}

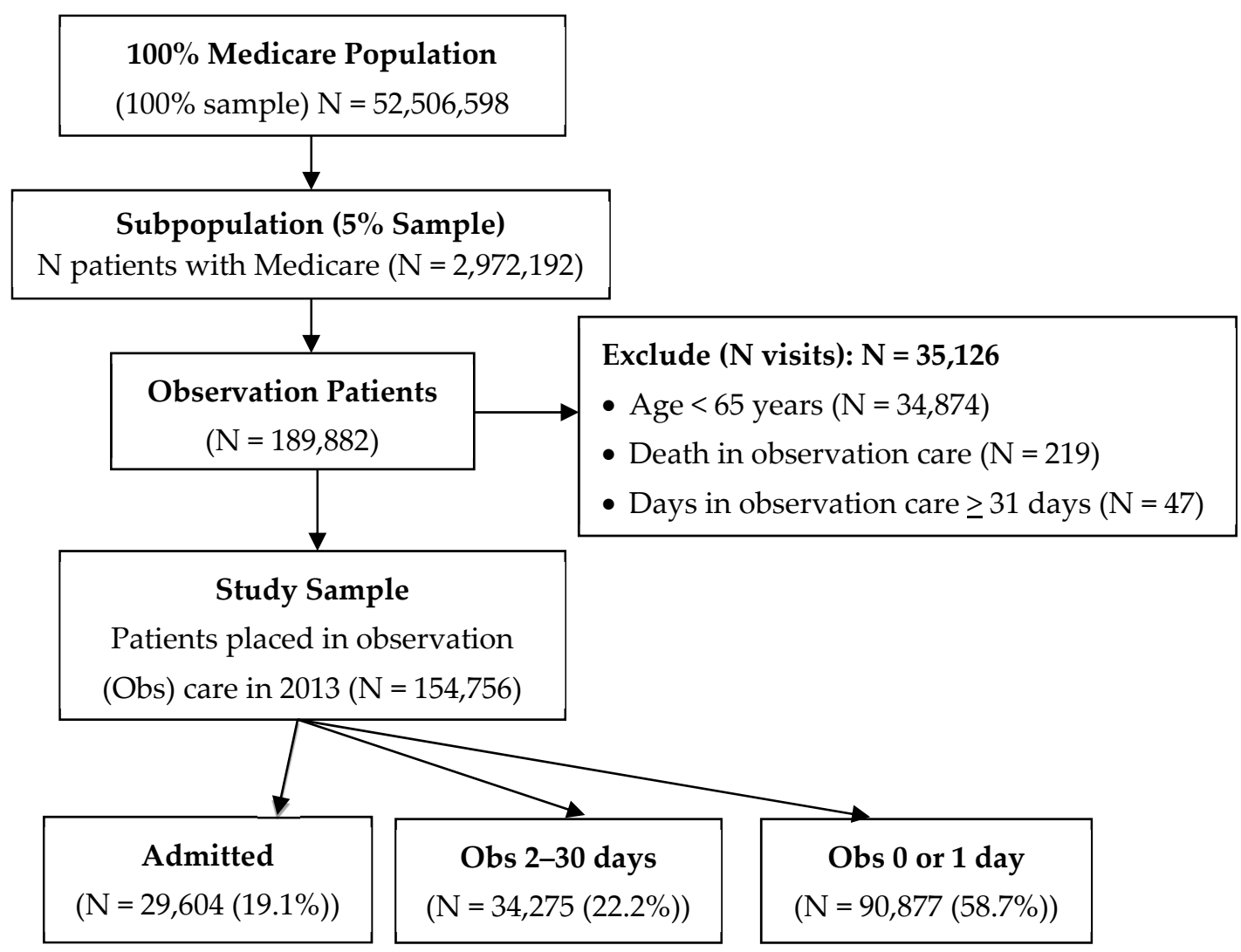

Figure A1. Study Cohort. The original sample of patients with Medicare insurance in 2013 is $52,506,598$ individuals. The "Subpopulation" is the 5\% sample distributed by the Centers for Medicare and Medicaid $(\mathrm{N}=2,972,192)$. Of the subpopulation, patients in observation care were selected. Of the patients in observation care, the study sample was selected following the application of the exclusion criteria. Of the study sample patients, $19.1 \%$ were admitted to the hospital, $22.2 \%$ had an observation stay of 2-22 days, and $58.7 \%$ had an observation stay of $0-1$ days. 
Table A1. CMS chronic Conditions.

\begin{tabular}{cc}
\hline Name of Chronic Condition & Variable Name in the Dataset \\
\hline Acute Myocardial Infarction & AMIc \\
Alzheimer's Disease & ALZHc \\
Alzheimer's Disease and Related Disorders & ALZH_DEMENc \\
Atrial Fibrillation & ATRIAL_FIBc \\
Cataract & CATARACTc \\
Chronic Kidney Disease & CHRONICKIDNEYc \\
Chronic Obstructive Pulmonary Disease & COPDc \\
Heart Failure & CHFc \\
Diabetes & DIABETESc \\
Glaucoma & GLAUCOMAc \\
Hip/Pelvic Fracture & HIP_FRACTUREc \\
Ischemic Heart Disease & ISCHEMICHEARTc \\
Depression & DEPRESSIONc \\
Osteoporosis & OSTEOPOROSISc \\
Rheumatoid Arthritis/Osteoarthritis & RA_OAc \\
Stroke/Transient Ischemic Attack & STROKE_TIAc \\
Breast Cancer & CANCER_BREASTc \\
Colorectal Cancer & CANCER_COLORECTALc \\
Prostate Cancer & CANCER_PROSTATEc \\
Lung Cancer & CANCER_LUNGc \\
Endometrial Cancer & CANCER_ENDOMETRIALc \\
Anemia & ANEMIAc \\
Asthma & ASTHMAc \\
Hyperlipidemia & HYPERLc \\
Benign Prostatic Hyperplasia & HYPERPc \\
Acquired Hypothyroidism & HYPERTc \\
& HYPOTHc \\
\hline
\end{tabular}

Table A2. Diagnosis codes.

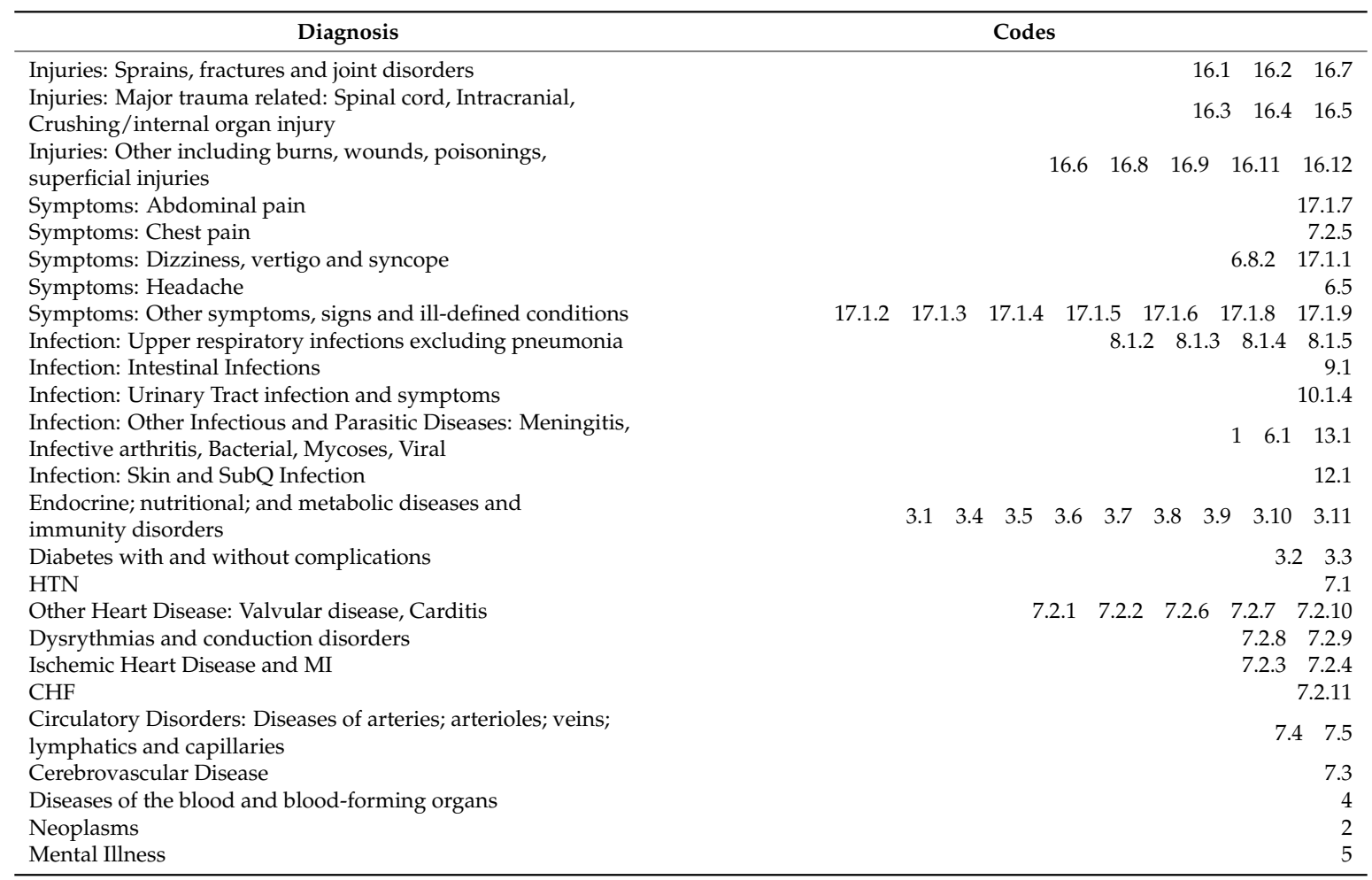


Table A2. Cont.

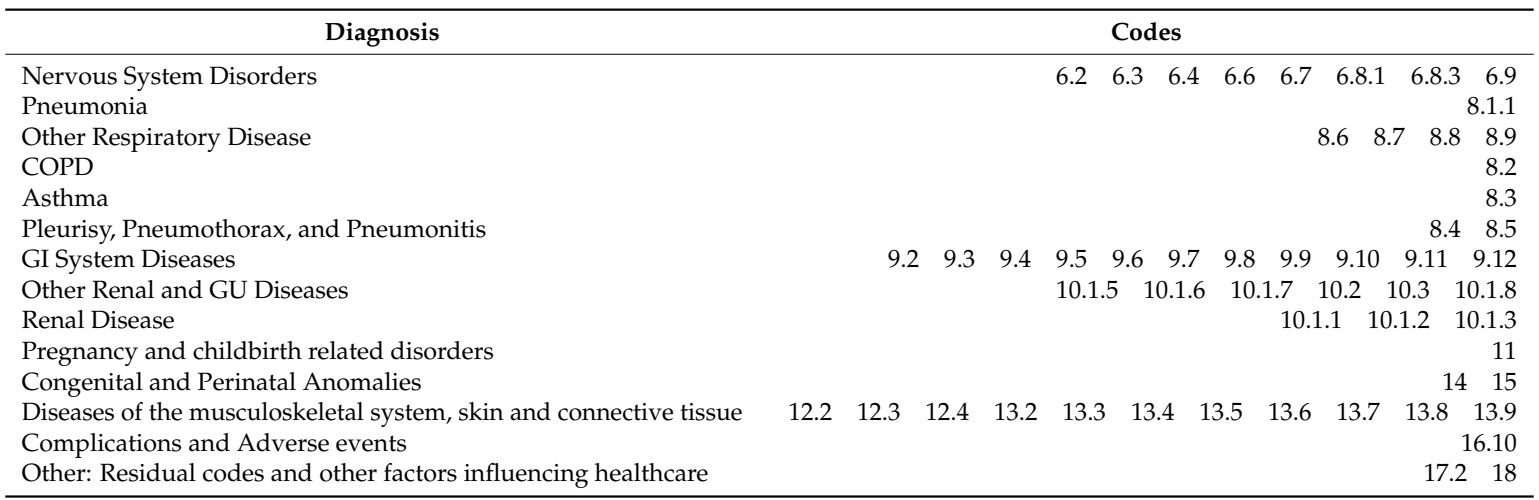

Based on the Clinical Classification Software (CCS) Multilevel ICD-9 codes devised by the Healthcare Cost and Utilization Project (HCUP).

\section{References}

1. Cafardi, S.G.; Pines, J.M.; Deb, P.; Powers, C.A.; Shrank, W.H. Increased observation services in Medicare beneficiaries with chest pain. Am. J. Emerg. Med. 2016, 34, 16-19. [CrossRef] [PubMed]

2. Feng, Z.; Wright, B.; Mor, V. Sharp rise in Medicare enrollees being held in hospitals for observation raises concerns about causes and consequences. Health Aff. 2012, 31, 1251-1259. [CrossRef] [PubMed]

3. Wright, B.; O'Shea, A.M.; Ayyagari, P.; Ugwi, P.G.; Kaboli, P.; Vaughan Sarrazin, M. Observation rates at veterans' hospitals more than doubled during 2005-13, similar to medicare trends. Health Aff. 2015, 34, 1730-1737. [CrossRef] [PubMed]

4. Centers for Medicare \& Medicaid Services. Part B hospital (including inpatient hospital Part B and OPPS). In Medicare Claims Processing Manual; Chapter 4; CMS: Baltimore, MD, USA, 2011. Available online: https: / / www.cms.gov / Regulations-and-Guidance/Guidance/Manuals/downloads/ / clm104c04.pdf (assessed on 21 November 2018).

5. Aston, G. Observation units: A tightrope act. Hosp. Health Netw. 2012, 86, 32-36. [PubMed]

6. Gabayan, G.Z.; Derose, S.F.; Asch, S.M.; Yiu, S.; Lancaster, E.M.; Poon, K.T.; Hoffman, J.R.; Sun, B.C. Patterns and predictors of short-term death after emergency department discharge. Ann. Emerg. Med. 2011, 58, 551-558. [CrossRef] [PubMed]

7. Gabayan, G.Z.; Asch, S.M.; Hsia, R.Y.; Zingmond, D.; Liang, L.; Han, W.; McCreath, H.; Weiss, R.E.; Sun, B.C. Factors associated with short-term bounce-back admissions following emergency department discharge. Ann. Emerg. Med. 2013, 62, 136-144. [CrossRef] [PubMed]

8. Gabayan, G.Z.; Sarkisian, C.A.; Liang, L.J.; Sun, B.C. Predictors of admission after emergency department discharge in older adults. J. Am. Geriatr. Soc. 2015, 63, 39-45. [CrossRef] [PubMed]

9. Clinical Classification Software (CCS) for ICD-9-CM. Available online: https:/ /www.hcup-us.ahrq.gov / toolssoftware/ccs/ccs.jsp (assessed on 21 January 2015).

10. Centers for Medicare \& Medicaid Services. Fact Sheet: Two-Midnight Rule. Available online: https: / /www.cms.gov /Newsroom/MediaReleaseDatabase/Fact-sheets/2015-Fact-sheets-items / 2015-07-01-2.html (accessed on 1 March 2017).

11. Diggie, P.J.; Heagerty, P.; Liang, K.Y.; Zeger, S.L. Analysis of Longitudinal Data, 2nd ed.; Oxford University Press: Oxford, UK, 2002.

12. Baugh, C.W.; Venkatesh, A.K.; Hilton, J.A.; Samuel, P.A.; Schuur, J.D.; Bohan, J.S. Making greater use of dedicated hospital observation units for many short-stay patients could save $\$ 3.1$ billion a year. Health Aff. 2012, 31, 2314-2323. [CrossRef] [PubMed]

13. Blecker, S.; Gavin, N.P.; Park, H.; Ladapo, J.A.; Katz, S.D. Observation units as substitutes for hospitalization or home discharge. Ann. Emerg. Med. 2016, 67, 706-713. [CrossRef] [PubMed]

14. Abrahamian, F.M.; Deblieux, P.M.; Emerman, C.L.; Kollef, M.H.; Kupersmith, E.; Leeper, K.V., Jr.; Paterson, D.L.; Shorr, A.F. Health care-associated pneumonia: identification and initial management in the ED. Am. J. Emerg. Med. 2008, 26, 1-11. [CrossRef] [PubMed] 
15. Kollef, M.H.; Shorr, A.; Tabak, Y.P.; Gupta, V.; Liu, L.Z.; Johannes, R.S. Epidemiology and outcomes of health-care-associated pneumonia: Results from a large US database of culture-positive pneumonia. Chest 2005, 128, 3854-3862. [CrossRef] [PubMed]

16. Shaughnessy, P.W.; Kramer, A.M. The increased needs of patients in nursing homes and patients receiving home health care. N. Engl. J. Med. 1990, 322, 21-27. [CrossRef] [PubMed] 